\title{
Concepts for a therapeutic prolongation of nephrogenesis in preterm and low-birth- weight babies must correspond to structural-functional properties in the nephrogenic zone
}

\author{
Will W. Minuth
}

\begin{abstract}
Numerous investigations are dealing with anlage of the mammalian kidney and primary development of nephrons. However, only few information is available about the last steps in kidney development leading at birth to a downregulation of morphogen activity in the nephrogenic zone and to a loss of stem cell niches aligned beyond the organ capsule. Surprisingly, these natural changes in the developmental program display similarities to processes occurring in the kidneys of preterm and low-birth-weight babies. Although those babies are born at a time with a principally intact nephrogenic zone and active niches, a high proportion of them suffers on impairment of nephrogenesis resulting in oligonephropathy, formation of atypical glomeruli, and immaturity of parenchyma. The setting points out that up to date not identified noxae in the nephrogenic zone hamper primary steps of parenchyma development. In this situation, a possible therapeutic aim is to prolong nephrogenesis by medications. However, actual data provide information that administration of drugs is problematic due to an unexpectedly complex microanatomy of the nephrogenic zone, in niches so far not considered textured extracellular matrix and peculiar contacts between mesenchymal cell projections and epithelial stem cells via tunneling nanotubes. Thus, it remains to be figured out whether disturbance of morphogen signaling altered synthesis of extracellular matrix, disturbed cell-to-cell contacts, or modified interstitial fluid impair nephrogenic activity. Due to most unanswered questions, search for eligible drugs prolonging nephrogenesis and their reliable administration is a special challenge for the future.
\end{abstract}

\section{Introduction}

The physiological adaption of a newborn baby to extrauterine life depends on many parameters including an intact morphological and functional development of the kidneys before and after birth [1]. Usually the complex process of nephron induction is completed at the time of birth. However, when a baby is born preterm or with low birth weight, the kidneys are still in a process of active nephrogenesis [2-4]. Autopsied preterm kidneys and a baboon model of preterm birth reveal that nephrogenesis is able to proceed for up to 3 weeks in extrauterine life [5].

Now, there is more and more evidence that preterm delivery is interfering the process of nephrogenesis

Correspondence: will.minuth@vkl.uni-regensburg.de

Institute of Anatomy, University of Regensburg, 93053 Regensburg, Germany resulting in oligonephropathy, which is estimated to be between 8 and 24\% [3, 4]. Pleiotropic noxae such as unbalanced metabolites, misleading morphogen signaling, inflammation, hyperoxigenation, low-protein diet, hypoperfusion, or nephrotoxic drugs are held accountable to cause it. Related pathologic data further exhibit that in neonatal kidneys, up to $18 \%$ morphologically abnormal glomeruli are present that illustrate a dilated Bowman's space and a shrunken glomerular tuft [6]. Most importantly, occurrence of such glomeruli is restricted to the outer renal cortex pointing out that the nephrogenic zone, involved stem cell niches, and the last nephron generation are affected.

A possible therapeutic aim for preterm and low-birthweight babies is to compensate impairment of nephrogenesis 
by medication and to stimulate morphogenic activity in the nephrogenic zone to prolong thereby nephrogenesis during early postnatal development [7]. However, all of the presently available data point out that such an approach is difficult to perform, since it must be adapted to peculiar structural and functional features contained in the nephrogenic zone [8]. Before doing so, there is also an urgent necessity of investigations dealing in human fetal kidney with the synthesis, secretion, and concrete transport of morphogens locally involved in maintenance of stemness and nephrogenesis [9]. Finally, since data for the application of drugs via the local blood supply and distribution in this peculiar environment is missing, a promising concept for prolongation of nephrogenesis is awaiting solid implementation.

\section{Review}

\section{View onto the nephrogenic zone}

During fetal growth of a mammalian kidney, the nephrogenic zone is restricted to the cortex corticis of parenchyma [10]. A factual problem is that randomly cut sections do not help to recognize essential structural details in microscopic analysis. Hence, to obtain comparable perspectives, a monopapillary kidney of a mouse, rat, or rabbit is divided in the middle between both poles for histological preparations. A human fetal kidney is cut best from the capsule towards the papilla of a lobus. Following this advice, the section plane shows the parenchyma in the cortices that is orientated along the lumen of the lining collecting duct (CD) tubules and perpendicular to the capsule (Fig. 1). Due to incomplete histological preservation, pathological specimens of a human kidney are often hard to interpret. To overcome some of the barriers, the nephrogenic zone of a neonatal rabbit fixed under controlled conditions shall serve here for illustration.

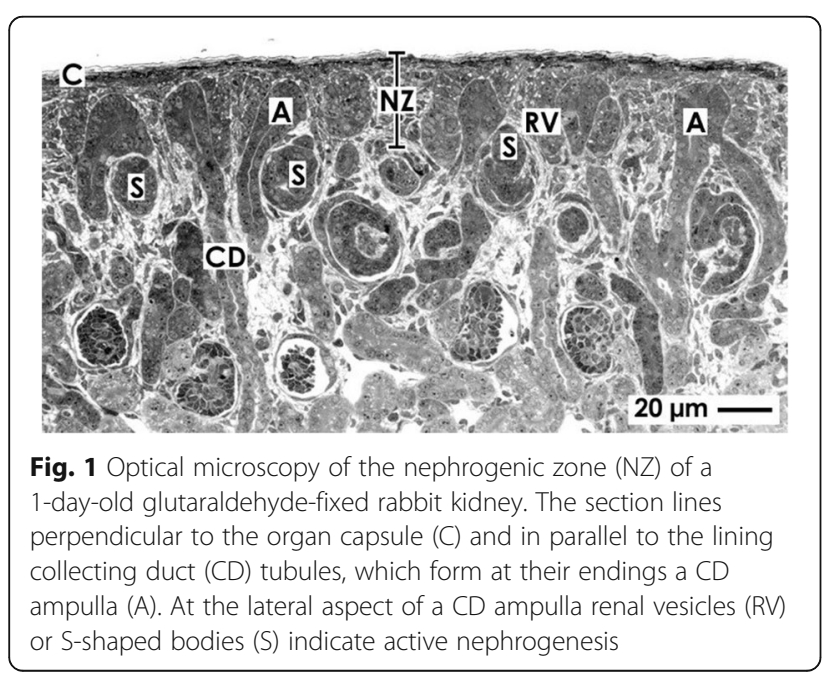

\section{Eccentric position}

The nephrogenic zone extends as a band along the entire surface of a fetal kidney and shows a width between 60 and $100 \mu \mathrm{m}$ depending on species [11]. Sections stained by hematoxylin-eosin solution present the nephrogenic zone as a "blue strip" [12]. Its outer aspect is covered by the organ capsule, while the inner side is facing maturing $\mathrm{CD}$ tubules and developing nephrons including first stages of arising glomeruli (Fig. 1). Located between these two limits, the complete cell biological machinery is contained here to maintain cell stemness, induction, and initial development of nephrons. Concrete tissues of the nephrogenic zone are the ureteric bud-derived collecting duct (CD) tubules, related branching sites including $\mathrm{CD}$ ampullae, the mesenchyme, and the capsule.

\section{Compartments}

As illustrated by low magnification, the outer border of the nephrogenic zone is the organ capsule (Fig. 1 and 2a). In homology to human, in neonatal rabbit kidney, it consists of a tunica fibrosa and a tunica muscularis [10]. Beyond the capsule, only two layers of metanephric mesenchymal (MES) stem cells occur. Beneath them and separated by a striking interface, $C D$ ampullae are aligned. All of them have the same orientation. Their tips have a distance of $14 \mu \mathrm{m}$ to the inner side of the organ capsule [13]. Further down and directed towards maturing nephrons, the dilated part of a $\mathrm{CD}$ ampulla continues to a neck and then to a shaft, which is connected with a differentiating CD tubule [14]. This site reflects the inner limit of the nephrogenic zone. Depending on the state of nephron formation at the upper later aspect of a CD ampulla, either mesenchymal cell condensation in the form of pretubular aggregates, polarized renal vesicles, or comma- or S-shaped bodies occur.

\section{Stem cell niches}

The capsule and the nephrogenic zone contain different kinds of stem cells (Fig. 2a). Mesenchymal stem cells occur as well in the capsule as in the underlying metanephric mesenchyme $[15,16]$. Epithelial stem cells are contained in the tip of a CD ampulla [17]. Since both parenchyma and stroma are developing from this pool, the capsule, mesenchymal as epithelial stem cells within the nephrogenic zone represent an extended stem cell niche that is covering the entire fetal kidney. In contrast, in a different definition, only the tip of a $\mathrm{CD}$ ampulla with contained epithelial stem/progenitor cells and some facing nephrogenic $\left(\mathrm{GDNF}^{+} / \mathrm{Six}^{+} / \mathrm{CITED}^{+}\right)$mesenchymal cells are regarded as an individual niche [18-20]. It is obvious that only this latter definition points to the site, where induction and initial formation of an individual nephron take place. 


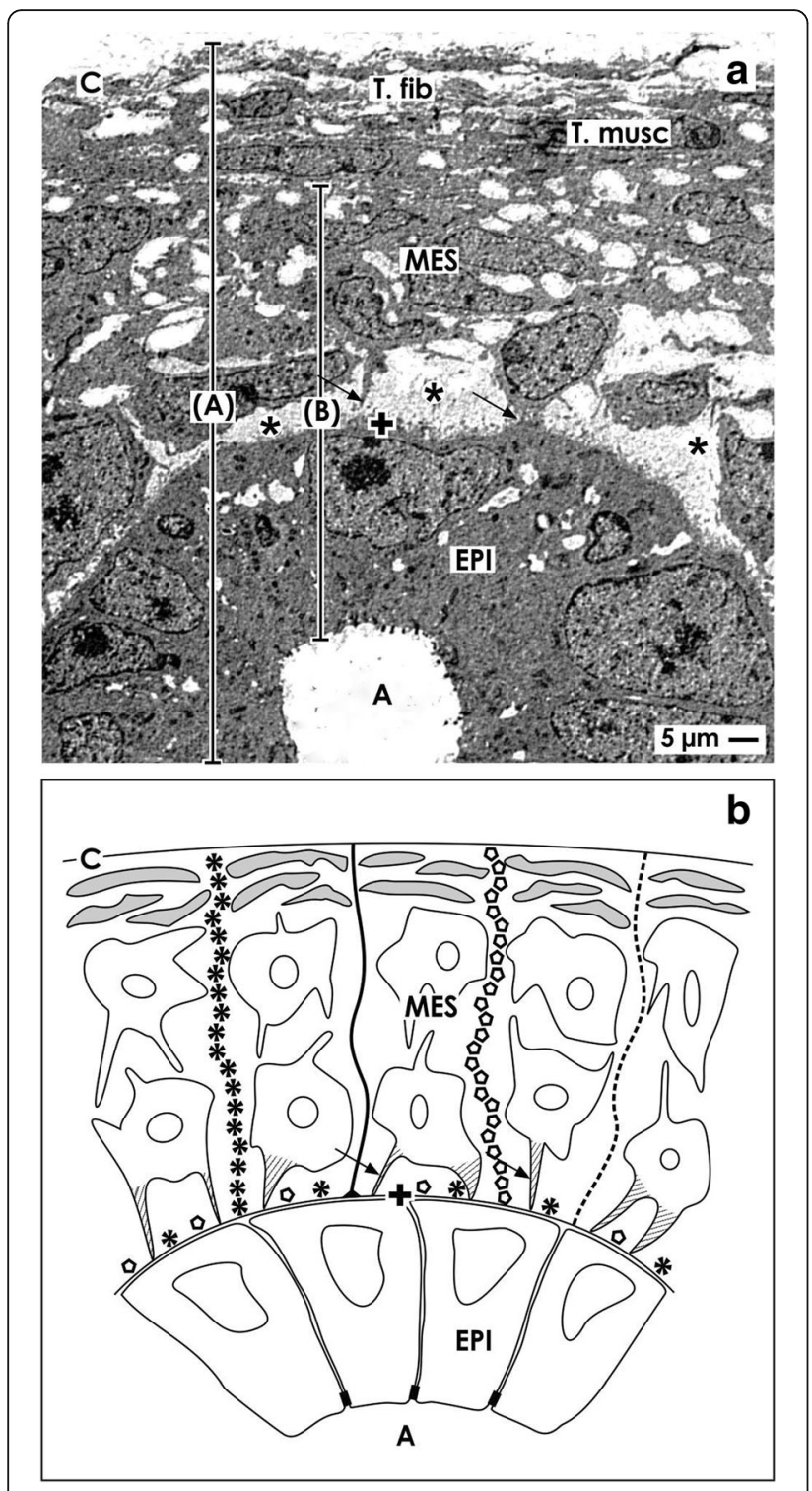

Fig. 2 Occurrence of stem cells in a 1-day-old and glutaraldehyde-fixed rabbit kidney shown by $\mathbf{a}$ transmission electron microscopy and $\mathbf{b}$ schema. a The capsule (C) consists of a tunica fibrosa (T.fib) and muscularis (T.musc). Epithelial (EPI) stem cells are enclosed in the tip of a CD ampulla (A) covered by a basal lamina (cross). An interface (asterisks) separates mesenchymal (MES) from epithelial stem cells. Projections of mesenchymal cells (arrow) cross it to contact a CD ampulla. Both the nephrogenic zone and the capsule can be seen as a niche that is covering the entire organ (A). In contrast, only the tip of a CD ampulla containing epithelial stem cells and some above positioned $\mathrm{GDNF}^{+} / \mathrm{Six} 2^{+} / \mathrm{CITED} 1^{+}$mesenchymal cells are regarded as a single niche (B). b Histochemistry exhibits that in the basal lamina of a CD ampulla tip, laminin $\gamma 1$ and agrin are contained. Further microfibers binding soybean agglutinin (SBA; black line) and anti-collagen type I (black asterisks), type II (light circles), and type III (dotted line) originate here to cross the interface and mesenchymal stem cells for fastening the capsule [10]

\section{Exact coordination during branching}

Development of renal parenchyma proceeds by a process, which is defined as branching morphogenesis
[21-23]. In a human kidney, the invading ureteric bud produces first the pelvis and calyceal sytems in the presumptive medulla. After formation of the ducts of Bellini, successive elongation of $C D$ tubules in the cortex takes place. Surprisingly, during radial extension of parenchyma, a change of the branching pattern in the inner and then in the outer cortex takes place [24]. Before birth, in the nephrogenic zone of a human and rabbit kidney, this spatiotemporal program raises in elongating $\mathrm{CD}$ tubules bifid branches. Their endings are orientated towards the covering mesenchyme. Since a branch exhibits a dilated form, it was specified as a CD ampulla. Actual investigations show that the process of $\mathrm{CD}$ tubule branching depends as well on the transcription factor Foxd1 as on the renin-angiotensin system (RAS) [25]. Related survival, proliferation, and primary differentiation of branching CD cells are influenced by fibroblast growth factors (FGFs) and retinoic acid (RA) [26].

For the human kidney, concrete data are lacking, but in the neonatal rabbit kidney, approaching of epithelial and mesenchymal stem cells is prescribed by microfibers that link the inner side of the organ capsule with the tip of the CD ampullae (Fig. 2b). In its basal lamina, laminin $\gamma 1$ and the proteoglycan agrin are contained. At this site also microfibers labeled by anti-collagen types I, II, III respectively soybean agglutinin (SBA) originate [10]. They span through the two layers of nephrogenic mesenchymal stem cells for mounting on the inner side of the capsule. This mechanic construction demonstrates that epithelial and mesenchymal stem cells do not meet by accident but are integral part of a guiding cage. It coordinates positioning at a distinct site and keeps contained cells close to the capsule.

Exact movement of involved cells within an individual niche is adjusted by the secreted bone morphogenic protein (BMP) antagonist Cerberus homologue1 (Cer1), Ret protooncogene (Ret), and ETS translocation variant4 (Etv4) $[17,27]$. By molecular positioning the tip of a $C D$ ampulla, the inner layer of the nephrogenic mesenchymal cells comes in close vicinity to the epithelial stem cells. While approaching, some of the mesenchymal cells acquire competence so that they can respond to morphogens. This operation is directed by protocadherin (cadherin family member14: FAT4/ dachsous cadherin related1: Dchs1) signaling [28]. Yet, epithelial stem cells in the tip of a $C D$ ampulla are exactly vis-à-vis of $\mathrm{GDNF}^{+} / \mathrm{Six} 2^{+} / \mathrm{CITED} 1^{+}$ mesenchymal cells $[19,20]$. When the exchange of morphogens was successful, only the group of induced mesenchymal cells separates, aggregates to become a pretubular aggregate, and performs a mesenchyme-to-epithelial transition (MET) to develop into a polarized renal vesicle at the lateral aspect of the related $\mathrm{CD}$ ampulla. For the remaining cells in the mesenchyme, the transcription 
factor Zeb1 is controlling the proceeding balance between proliferation, migration, and apoptosis [29].

When impairment of nephrogenesis in the kidney of preterm infants is under debate, remodeling of illustrated microfibers appears to be an important issue (Fig. 2b) [30]. This process requires tissue transglutaminases (TGases), matrix metalloproteinases (MMPs) and membrane targeted MMPs (MT-MMPs) controlling synthesis, and degradation of extracellular matrix [31, 32]. An equilibrated activity of those TGases directs also growth factor-stimulated signaling and in turn cell proliferation $[33,34]$. Whether the balance of TGase activity on microfibers or on the basal lamina of a CD ampulla tip is disturbed and intrinsic activity within renal stem cell niches of preterm infants is impaired thereby, waits for investigation. However, when an increased activity is detected, therapeutic application of inhibitors of TGases may help to find back to an intact equilibrium between synthesis and degradation [35].

\section{Separation of stem cells by an interface}

For induction of a nephron, epithelial and mesenchymal cell bodies within the niche are approaching but stand at a distance between 1 to $2 \mu \mathrm{m}$ (Figs. 2a and 3a) [36, 37]. This special configuration was recorded as well by optical microscopy [38-41] as transmission electron microscopy (Fig. 2a and 3) [42-45]. Although less considered, it is present in mouse, rat, rabbit, and human kidneys. Moreover, ultrastructural analysis exhibits that a basal lamina covers the tip of a CD ampulla. Its lamina fibroreticularis consists of a remarkable fibrillar meshwork [46]. Further projections (also called cytonemes, signaling filopodia, protrusions) of mesenchymal cells cross the interface to penetrate the basal lamina and to contact the basal plasma membrane of epithelial stem cells (Figs. 2a and 3a). Surprisingly, the interface looks blank, when conventional fixation by glutaraldehyde (GA) solution for transmission electron microscopy is used. However, numerous braces of proteoglycans on the surface of projections and on the basal lamina become visible, when fixation of specimens is performed by GA solution including cupromeronic blue (Fig. 3b) [47]. Application of GA solution including ruthenium red (Fig. 3c) or tannic acid (Fig. 3d) unveils earlier unseen textured extracellular matrix [37]. Comparable to before mentioned microfibers, one has to imagine that any disparity in synthesis or degradation of illustrated extracellular matrix at the interface will impair nephrogenesis due to disturbed binding of morphogens as it is described later.

\section{Contacts between cells}

Although the bodies of mesenchymal and epithelial stem cells are separated by a striking interface, projections of

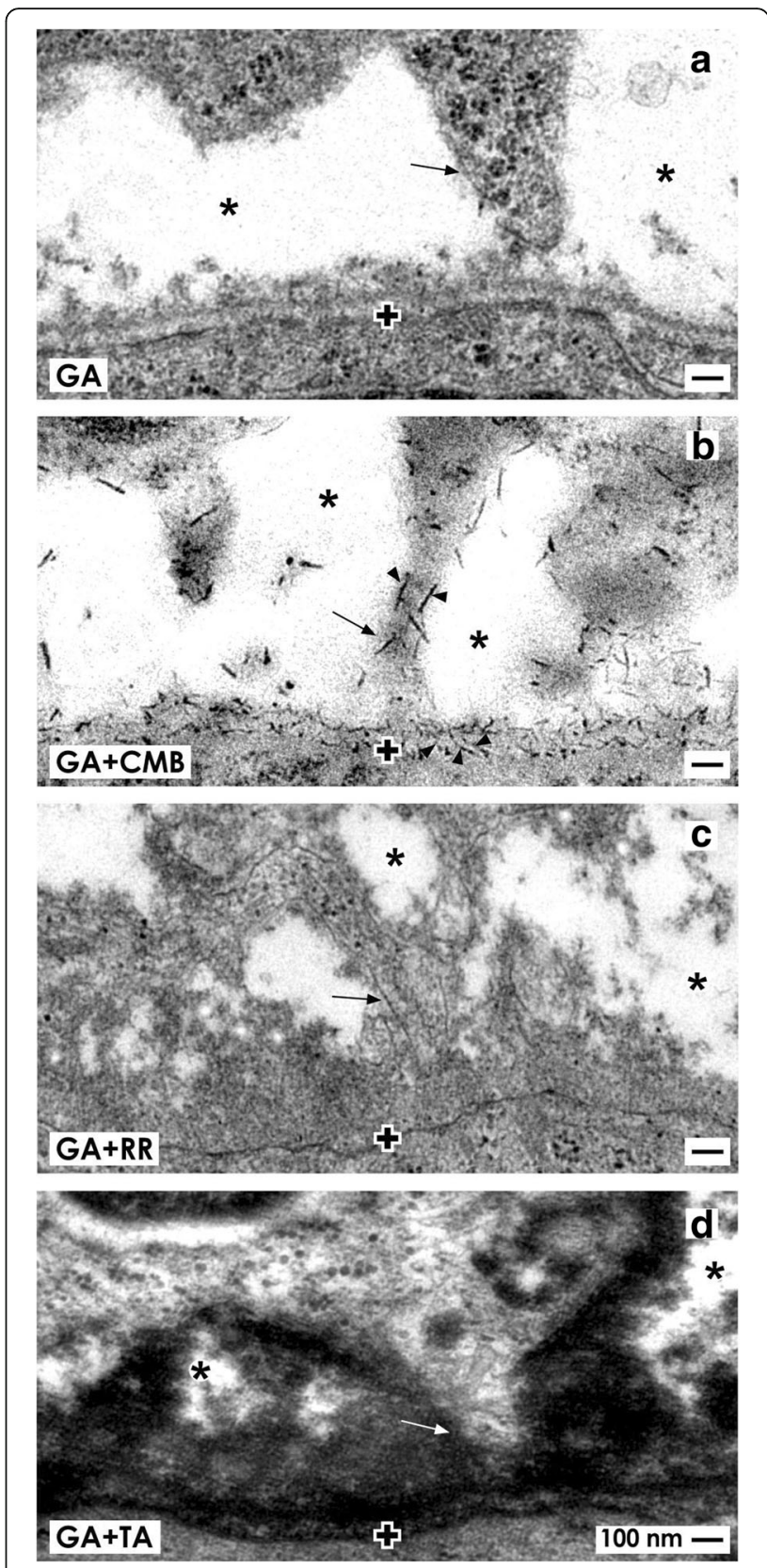

Fig. 3 Transmission electron microscopy of a 1-day-old and glutaraldehyde-fixed rabbit kidney depicts mesenchymal cell projections (arrow) contacting epithelial cells and unveils extracellular matrix at the interface of the renal niche. a Specimens fixed by conventional glutaraldehyde (GA) solution illustrate a clear interface (asterisk). b In contrast, fixation by glutaraldehyde solution including cupromeronic blue (CMB) shows that numerous braces of proteoglycans are recognized on the surface of cell projections and within the basal lamina (arrow head) of epithelial stem cells. c Specimens fixed by GA solution including ruthenium red (RR) or $\mathbf{d}$ tannic acid (TA) unmasks further textured extracellular matrix at the interface and basal lamina of a CD ampulla, which is labeled by a cross 
mesenchymal cells cross it, to establish a contact at the tip of a CD ampulla (Figs. 2a and 3) [48]. Earlier, it was reported that at this site, integrin $\alpha 8 \beta 1$ is localized, which binds to nephronectin on the basal lamina covering epithelial stem cells [49-51]. In addition, the microtubule-dependent motor protein kinesin (KIF26B) is established here to control cell attraction, signal transduction, and developmental patterning [52-54].

Moreover, new data show that a mesenchymal cell projection penetrates the basal lamina of epithelial stem cells. Its distal portion is in contact with extracellular matrix that creates a special sleeve [48]. Between the end of a mesenchymal cell projection and the basal plasma membrane of an epithelial stem cell, tunneling nanotubes are established (Fig. 4). This essential finding points to a concrete path between mesenchymal and epithelial cells that is optimally suited for cell-to-cell communication including the transport of a variety of molecules [55]. While in transmission electron microscopy, the moment an actual physiological status is frozen, actual timelaps imaging shows that mesenchymal cells are motile so that they attach and detach from the CD ampulla tip across time [56]. One can imagine that any disturbance of anchorage or communication between mesenchymal and epithelial stem cells including restricted functionality in cell projections and/or tunneling nanotubes will impede nephron induction.

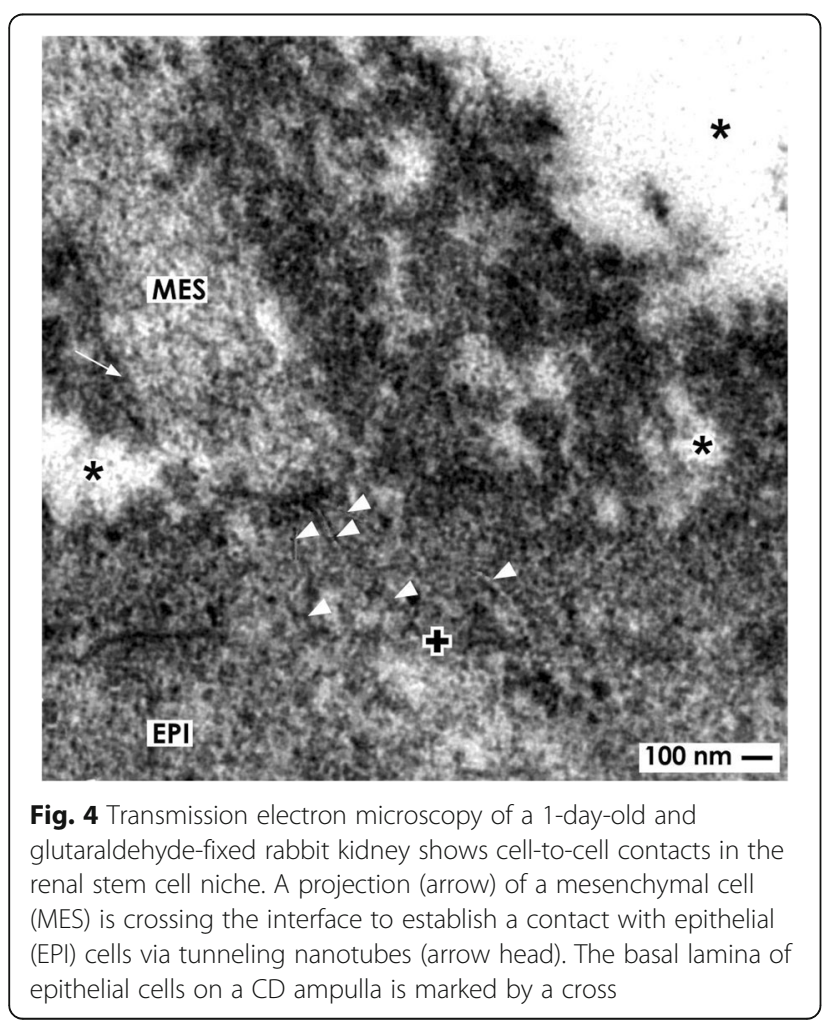

\section{Minimal vascular supply}

It is hard to believe, but the incomplete vascular supply is a unique feature of the nephrogenic zone. Earlier performed histochemistry with Ulex europaeus I lectin on human fetal kidneys informs that in the area of starting nephrons, not intact capillaries but only strands of spreading endothelial cells exist [57]. In a neonatal rabbit kidney, it was recorded by immunohistochemistry that capillaries line from cortical radiate arteries towards the cortex corticis. Forming vessels are recognized on developing glomeruli. Further strands of endothelial cells line at the lateral aspect of a CD ampulla to the lower cleft of S-shaped bodies, where the glomerular tuft is arising (Fig. 5) [58]. Actual immunohistochemical data with the endothelium marker anti-CD 31 exhibits that cell strands of forming vessels occur at the branching site of the CD tubule and at the lateral aspect of a CD ampulla [59, 60]. However, at the niche site including the tip of a CD ampulla and neighboring mesenchymal stem/progenitor cells, endothelial cells are not present.

Expression of endothelial nitric oxide synthase was detected in the kidney of a rat on developing S-shaped bodies, but not within the mesenchymal cell layers [61]. In homology to the ureteric bud, it appears most probable that Wingless Int-1 (Wnt7b) protein expressed by epithelial stem cells at the lateral aspect of CD ampullae activates canonical Wnt signaling in the surrounding interstitial cells to establish capillaries [62]. An actual investigation on developing mouse kidney exhibits that forming vessels at the nephrogenic zone remain unperfused, although oxygenation is able to drive nephron progenitor differentiation $[63,64]$. Finally, also capillaries within the capsule produce interstitial fluid to transport it in a complex tunnel system towards the outer side of the nephrogenic zone (Fig. 5) [10].

\section{Integrated signaling of morphogens}

Growth factors or more precisely morphogens are highly bioactive molecules, which control stem cells within the nephrogenic zone and individual niches during development of the kidney [65]. This complex task comprises regulation of stemness, cell proliferation, targeted migration, competence, induction, and primary formation of nephrons [9]. In a human kidney, this process is active from the beginning of organ anlage up to birth, while in other mammalian species, nephrogenesis can proceed during the early postnatal period [7].

More general tasks such as supervising of survival, stemness, and proliferation of stem cells in the nephrogenic zone is triggered for example by morphogen mouse double minute 2 homolog (Mdm2). Its successful signaling results in expression of site-specific markers such as amphiphysin, Cited1, Sall1, and Pax2 [66]. 


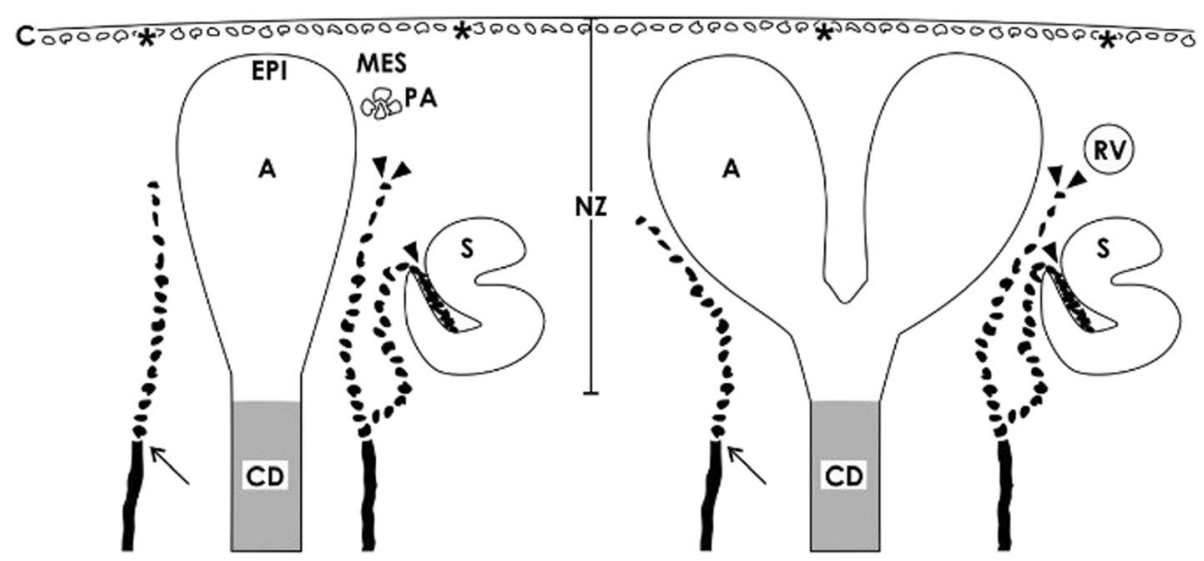

Fig. 5 Schematic illustration informs about the incomplete vascular supply of the nephrogenic zone (NZ) in a neonatal rabbit kidney. Label by antibody EC1 [58] depicts that endothelial cells arise from cortical radiate arteries (arrow) lining in parallel to the collecting duct (CD) tubules. Endothelial cells (arrow heads) migrate to the lateral aspect of an ureteric bud derived CD ampulla (A) and to the lower cleft of a S-shaped body (S). In addition, cells of the tunica muscularis within the organ capsule (C) form intracellular and extracellular tunnels (asterisks) for production of interstitial fluid [10]. It is obvious that the area of the niche including the tip of a CD ampulla with epithelial (EPI) cells and neighboring mesenchymal cells (MES) is avascular. PA pretubular aggregate, RV renal vesicle

A clearly focused role has morphogens, which operate competence, induction, and subsequent nephron formation. It starts when an elongating $\mathrm{CD}$ tubule divides into bifid branches to form CD ampullae [67]. To make signaling of a morphogen successful, on neighboring mesenchymal cells, the time slot for competence must open. In that case, morphogen BMP7 makes possible that related mesenchymal stem cells principally can answer an inductive signal [68]. However, during the process of nephron induction, not all $\mathrm{GDNF}^{+} / \mathrm{Six} 2$ ${ }^{+} / \mathrm{CITED}^{+}$mesenchymal cells will respond, but only those that are exactly facing epithelial cells contained in the tip of a CD ampulla $[19,20]$. Downregulation of Six2 + by knockdown of neurofibromin with small interfering RNAs results in loss of competence, lack of nephron induction, and an increased ratio of apoptotic cells [69]. Further repetitive nephron induction requires an adequate pool of competent cells at the right time and place. If reduced, it is refilled by self-renewing of progenitor cells in the nephrogenic zone operated by intact Six $2^{+}$expression [70, 71].

When a correct number of competent nephrogenic mesenchymal cells in a niche is available, induction of a nephron takes place. It is triggered by complex signaling of locally synthetized morphogens [9, 65]. Since site of their expression and receptors on target cells are in many cases not identical, morphogens are transported between competent mesenchymal and epithelial stem cells contained in the tip of a CD ampulla (Figs. 2, 3, and 4). The main players in this concert are bone morphogenetic proteins (BMP4, BMP7), fibroblast growth factor (FGF8), glial cell line-derived neurotrophic factor (GDNF), Wnt family members (Wnt4, Wnt5a, Wnt9b), related receptors, and involved modulators [9, 65]. A list of them acting in chronical sequence between induction of competent mesenchymal cells and formation of a polarized renal vesicle is presented in Table 1.

When signaling of involved morphogens was successful, a small group of induced $\mathrm{GDNF}^{+} / \mathrm{Six}^{+} / \mathrm{CITED}^{+}$mesenchymal cells separates and aggregates to perform a mesenchymal-to-epithelial transition (MET) on the upper lateral aspect of a related CD ampulla. Running nephrogenesis is histologically recognized first by signs of cell condensation, formation of a pretubular aggregate, and then development of a renal vesicle $[19,20,72]$.

\section{Morphogens must reach related receptors}

Previously, one believed that epithelial and mesenchymal stem cells within the renal niche meet by chance and that transport of morphogens occurs by diffusion. It was further speculated that the distance between interacting cells can be neglected [9, 67]. Under these circumstances, a sharp gradient principally can arise and an effective concentration of a secreted morphogen will reach its related receptor [73]. However, these arguments are pure speculations and were not investigated for the renal niche.

Clear but little noticed hints about the transport of a morphogen provide transfilter culture experiments. For example, NIH3T3 mouse embryo fibroblast cells expressing morphogen Wnt4 were cultured for tubule induction on the one side, while isolated nephrogenic mesenchyme was placed on the other side of a filter [74]. It was demonstrated that separating filters with pore sizes of $0.1 \mu \mathrm{m}$ and above support induction including tubule formation, while pores of $0.05 \mu \mathrm{m}$ abolish 
Table 1 List of selected morphogens acting during the initial phase of nephrogenesis

\begin{tabular}{|c|c|c|c|c|}
\hline Morphogen & Function & Expression site & Receptor in target & References \\
\hline Wnt9b & $\begin{array}{l}\text { Induction of nephrogenesis, mesenchymal-to- } \\
\text { epithelial transition (MET) }\end{array}$ & CD ampulla & $\begin{array}{l}\text { FZD (Frizzled)/LRP receptor-related protein in } \\
\text { mesenchyme }\end{array}$ & [97] \\
\hline BMP4 & Prevention of ectopic branching of CD tubule & Mesenchyme & $\begin{array}{l}\text { Activin-like kinase 3/6 (Alk)/type } \| \text { receptor in CD } \\
\text { ampulla }\end{array}$ & [131] \\
\hline BMP7 & $\begin{array}{l}\text { Branching of } C D \text { ampulla, competence and } \\
\text { receptivity in mesenchyme }\end{array}$ & Mesenchyme & $\begin{array}{l}\text { Activin-like kinase } 3 / 6 \text { (Alk)/type } \| \text { receptor in CD } \\
\text { ampulla in mesenchyme }\end{array}$ & {$[68,131]$} \\
\hline GDNF & $\begin{array}{l}\text { Elongation of CD tubule, branching of CD } \\
\text { ampulla, site-specific cell proliferation }\end{array}$ & Mesenchyme & $\begin{array}{l}\text { Receptor tyrosine-protein kinase (Ret)/GDNF f-mily } \\
\text { receptor Alpha } 1 \text { (GFRa1) in CD ampulla }\end{array}$ & [80] \\
\hline Wnt5a & $\begin{array}{l}\text { Clear position of mesenchyme, induction of } \\
\text { nephrogenesis }\end{array}$ & CD ampulla & $\begin{array}{l}\text { FZD (Frizzled)/LRP receptor-related protein In } \\
\text { mesenchyme }\end{array}$ & [132] \\
\hline Wnt4 & $\begin{array}{l}\text { Induction of nephrogenesis, mesenchymal-to- } \\
\text { epithelial transition (MET) }\end{array}$ & $\begin{array}{l}\text { Condensing } \\
\text { mesenchyme } \\
\text { Pretubular aggregate }\end{array}$ & $\begin{array}{l}\text { FZD (Frizzled)/LRP receptor-related protein in } \\
\text { mesenchyme }\end{array}$ & {$[74,133]$} \\
\hline Fgf8 & $\begin{array}{l}\text { Transition of induced mesenchyme into } \\
\text { pretubular aggregate and renal vesicle }\end{array}$ & $\begin{array}{l}\text { Mesenchyme } \\
\text { Renal vesicle }\end{array}$ & $\begin{array}{l}\text { Fibroblast growth factor receptor } 1 \text { and } 2 \text { (Fgfr1/2) } \\
\text { in mesenchyme }\end{array}$ & {$[98,103,134]$} \\
\hline
\end{tabular}

it. One must consider that morphogens are so small molecules that they can cross a pore of this diameter without any problem. It may surprise but solubilized morphogen molecules in form of a supernatant from Wnt4 expressing cells were not able to induce formation of tubules in isolated nephrogenic mesenchyme. Thus, the transport of a morphogen during induction of a nephron does not work exclusively by simple diffusion but appears to be more complex [75].

Moreover, earlier morphological findings show cell-tocell contacts between mesenchymal and epithelial stem cells in niches of embryonic kidney [76] and further transfilter culture experiments [77]. This basic finding shows that cell-to-cell communication exists and contradicts the general assumption that all of the involved morphogens are transported by diffusion. Actual morphological hints for a complex transport of morphogens are the spatial separation of mesenchymal and epithelial cell bodies in the niche and contacting mesenchymal cell projections (Figs. 2 and 3). Further, a striking interface filled with textured extracellular matrix and a basal lamina covering epithelial cells at the tip of a CD ampulla must be considered (Fig. 3b-d) $[8,48]$. It is obvious that such an environment impedes diffusion and enables selective binding of morphogens during their transport on extracellular matrix [78]. In addition, contacts between mesenchymal and epithelial cells via cell projections including tunneling nanotubes makes it most probable that a route for a dosed transport of various molecules exists (Figs. 2, 4, and 5) [79].

Finally, regarding not one but different kinds of transported morphogens, one has to consider that each of them has different molecular properties. They can be sorted according to good [19, 80, 81], minor $[82,83]$, and poor [84-86] solubility in saline solution [87]. Following this schema of sorting (Fig. 6), it is possible to allocate the transport of involved morphogens to recently detected morphological features (Figs. $2,3,4)$. Since concrete data for the human renal stem cell niche are not available, the suggested concept here is based on morphological findings raised in

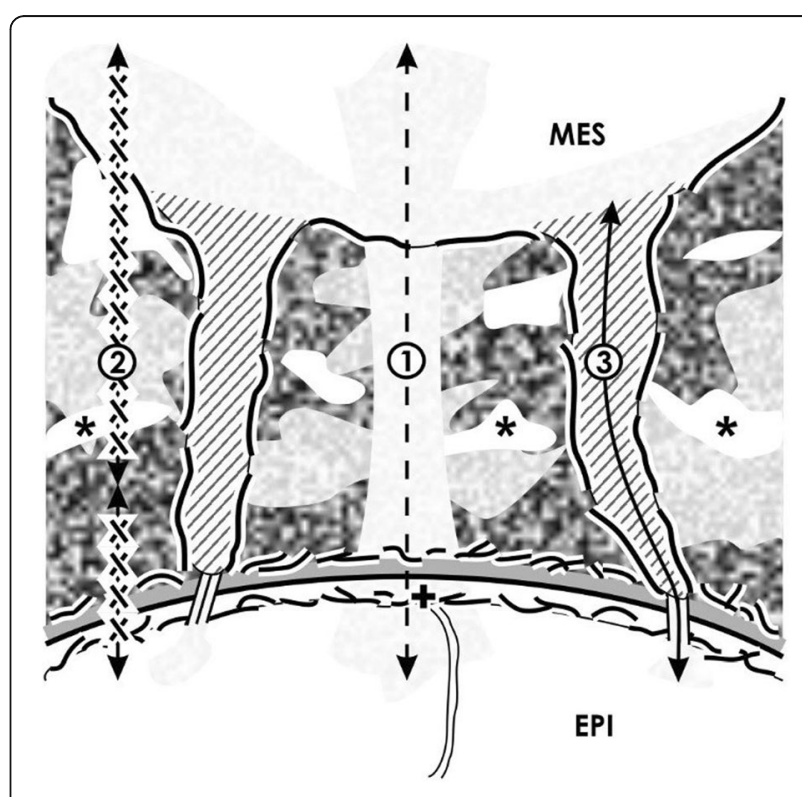

Fig. 6 Schematic illustration informs about three possible routes for the transport of morphogens within the renal stem cell niche. Mesenchymal (MES) and epithelial (EPI) cells are separated by an interface (asterisk) including textured extracellular matrix. Projections of mesenchymal cells cross it to establish cell-to-cell contacts via tunneling nanotubes. On this situation, it is speculated that morphogens with good solubility are transported by diffusion (1). Morphogens with minor solubility are secreted in interstitial fluid and then bound on extracellular matrix, where they are delivered on demand (2). Morphogens with poor solubility are transported in cell projections and tunneling nanotubes (3). The basal lamina of epithelial stem cells at the tip of a CD ampulla is labeled by a cross 
neonatal rabbit kidney and data collected from other developmental systems [88, 89].

\section{Ultrastructure restricts transport of morphogens}

Fixation of specimens with glutaraldehyde (GA) solution including cupromeronic blue, ruthenium red, or tannic acid for transmission electron microscopy demonstrates textured extracellular matrix at the interface of the renal stem cell niche (Fig. 3b-d) [87, 88]. A complementary but only very little space does not show any label, appears to contain only interstitial fluid, and is consequently best suited for diffusion of molecules (Fig. 6.1). The sole candidate for a morphogen sprayed here is GDNF. The molecule contains 134 amino acids, it is secreted as a glycoprotein and it is well soluble in interstitial fluid [90]. According to literature, only GDNF synthesized by mesenchymal stem cells was up to date defined as a long-distance diffusible morphogen that binds on Ret tyrosine kinase receptor and a co-receptor GFR $\alpha 1$ localized at the tip of a CD ampulla $[19,91]$.

As mentioned, the available volume for long-distance diffusion of GDNF is unexpectedly small. In contrast, histochemical label of cupromeronic blue on mesenchymal cell projections and on the basal lamina covering epithelial stem/progenitor cells illustrates an unexpected amount of syndecans and/or glypicans (Fig. 3b), while label by ruthenium red (Fig. 3c) or tannic acid (Fig. 3d) points to perlecans and other proteins of extracellular matrix [92]. Recently published literature shows that especially proteoglycans exhibit a high affinity for morphogens and that they are able to modulate kidney development by interacting with GDNF, molecules of the FGF and TGF $\beta$ superfamilies, EGF receptor ligands, and HGF [93-96]. The present concept for the renal niche is that binding of individual morphogens on proteoglycans can be regarded as a "morphogenic switch" that triggers either as an inhibitor or as a facilitator the fine-tuning of a gradient and in turn the bioavailability of a morphogen (Fig. 6.2). This assumption is underlined by the fact that environment lacking heparan sulfate proteoglycans (HSPGs) does not support formation of an effective Wnt gradient abolishing in turn further development [92].

Other morphogens such as Wnt4, Wnt5a, and Wnt9b control renewal and differentiation of nephron progenitor cells, CD ampulla branching, and nephron induction $[9,97$, 98]. One has to consider that Wnt molecules have posttranslational modifications in the form of a saturated palmitic acid and an unsaturated palmitoleic acid resulting in a poor solubility in saline impeding diffusion in interstitial fluid from one cell to the other [85]. There are hints that Wnt molecules are not secreted into interstitial fluid for further diffusion but are presented by epithelial cells near contacting mesenchymal cell projections. By this mechanism, Wnt molecules can immediately reach the plasma membrane of the target cell to find a directed cargo $[99,100]$. Tkv-GFP receptor puncta of cell projections in Drosophila were shown to move here either in an anterograde or in a retrograde direction (Fig. 6.3) [101].

Morphogen sonic hedgehog (Shh) controls renal patterning [102, 103]. This kind of morphogen is not secreted into the interstitium but is distributed in the form of a particle that remains associated during transport with the surface on cell projections (Fig. 6.3) [104, 105].

Bone morphogenic proteins (BMPs) are morphogens with poor solubility in interstitial fluid [19]. For this reason, the transport of a BMP molecule from one cell to the other by diffusion in the interstitial fluid is unlikely. Instead, transport of BMPs at the contact site between a mesenchymal cell projection and an epithelial cell appears to be more probable (Fig. 6.3). At such cell contacts, released BMP molecules can bind on the plasma membrane for transport on receptors as it was demonstrated for Drosophila Tkv [106, 107].

\section{Tunneling nanotubes can direct controlled distribution}

Actual morphological data exhibit that projections of mesenchymal stem cells cross the interface of a renal niche to penetrate the basal lamina and to contact the basal aspect of epithelia cells at the tip of a CD ampulla (Fig. 3a and 4) $[87,88]$. In addition, between the end of a mesenchymal cell projection and the basal plasma membrane of an epithelial cell, tunneling nanotubes establish a basic functional cell-to-cell contact (Figs. 4 and 6.3). Occurrence of nanotubes at this specific site points out that in the niche, an up-to-date not considered bidirectional cargo system for organelles, membrane compounds, and other kinds of molecules exists [108-113].

Transport functions in the renal niche related to tunneling nanotubes were not under analysis up to date. Instead, other kinds of renal cells kept in culture were used to investigate cell-to-cell communication [55, 114]. Precise ligand distribution via cell-to-cell contacts and signaling filopodia was demonstrated for BMP2 and Wnt morphogens $[115,116]$. Although yet not examined, it appears most likely that morphogens are transported in the renal niche this way, at the correct site and time, and in sufficient amount to maintain stemness and to initiate nephron induction (Fig. 6.3) [87, 88, 117].

\section{Export by vesicles}

Beside described routes, it is also suspected that the transport of morphogens between cells takes place by vesicles such as exosomes $(40-100 \mathrm{~nm})$ or microvesicles $(100-1000 \mathrm{~nm})$ [118-120]. In such particles, principally as well mRNA, microRNA as synthesized morphogens can be shuttled [121-124]. Although demonstrated for 
regenerative processes in the kidney, with exception of morphogen Shh, literature is not available that informs about transport of morphogens by vesicles within the nephrogenic zone and contained niches [104, 105].

\section{Biomedicine encounters the nephrogenic zone}

New literature exhibits that quite different influences can cause impairment of nephrogenesis in preterm and low-birth-weight babies [125]. It is obvious that independent from chemical nature, all of those hampering effects finally join the nephrogenic zone and affect the here contained niches. As described before, it is the definitive scene, where maintenance of stemness, precise positioning of cells, nephron induction, and initial development of nephrons are controlled. Consequently, therapeutic concepts prolonging nephrogenesis for preterm and low-birth-weight babies encounter inevitably the peculiar microanatomy of the nephrogenic zone, the complex interactions between nephrogenic mesenchymal and epithelial stem cells including the intact signaling of involved morphogens. In this situation, it is a consequent step to think about a therapeutic administration of morphogens. However, one must keep in mind that the here acting morphogens are on the one hand highly bio-effective molecules. On the other hand, one has to consider that a therapeutic use might be associated with hidden biomedical risks. For example, exogenously applied GDNF promotes formation of unwished ectopic ureteric buds [126].

Following notions for a therapeutic prolongation of nephrogenesis, the nephrogenic zone, contained niches, the bodies of mesenchymal and epithelial stem cells, their spatial separation by a striking interface, peculiar extracellular matrix, and cell-to-cell contacts via mesenchymal cell projections including tunneling nanotubes must be seen as a unique structuralfunctional ensemble (Figs. 2 and 3) [87, 88]. One has also to take into account that this area does not act autonomously but is under control of a set of morphogens with quite different biophysical features [9]. The actual problem is that about stimulation respectively inhibition of morphogen synthesis, secretion, and binding on extracellular matrix during local transport, only little concrete information is available. In other words, a site-specific therapy for the nephrogenic zone including the niches for prolongation of nephrogenesis in preterm infants needs first scientific answers to unsolved questions and then a critical selection of eligible drugs. Imaginable is either administration of a drug that stimulates the synthesis of the described genuine morphogens within the nephrogenic zone or administration of pharmacologically active morphogens by a smart drug delivery system.

\section{Safe drug delivery is the challenge}

Due to an incomplete vascular supply, the nephrogenic zone is a bradytroph district (Fig. 5) [58-60]. At the site of stem cell niches, no intact vessels occur. This up-todate less considered fact is a basic obstacle for a local drug administration prolonging nephrogenesis. Perhaps, it will be possible in the future to transport drugs via cortical radiate arteries and/or via the rete capsularis including the tunnel system [10]. In other words, first, it must be experimentally elaborated whether an administered drug shows a better distribution from the outer cortex or from the capsule side towards the nephrogenic zone.

In addition, morphogens such as GDNF or FGF8 with a good solubility in saline have a chance to reach niche sites by diffusion (Figure 6.1). For morphogens such as BMP4 or BMP7, a therapeutic administration will be more difficult, since secreted BMPs are transported by restricted diffusion and interaction with extracellular matrix (Fig. 6.2). Thus, in this case, not by the therapeutic administration of a drug but by the local extracellular matrix within the niche is decided upon free accessibility to the related receptor. For morphogens such as Wnt4, Wnt5a, Wnt9b, or Shh, an administration and action on the target cells becomes unpredictable. These morphogens are not soluble in saline solution and can bind optionally on extracellular matrix and on cell projections [74]. Transport of the mentioned morphogens is also thinkable along the plasma membrane and via tunneling nanotubes (Fig. 6.3) [127-129]. Possibly, isolation and culture of the nephrogenic zone in its original composition will help in a first issue to solve some of the mentioned problems [130].

\section{Conclusions}

Preterm and low-birth-weight babies are suffering frequently on impaired nephrogenesis causing in turn oligonephropathy with lifelong disease risks. Consequently, a reliable pharmacological concept prolonging nephrogenesis is urgently required. However, due to incomplete vascular supply, complex microanatomy, and diverse signaling of morphogens, a site-specific drug administration in the nephrogenic zone will be a particular challenge. Thus, a drug may act, when it exhibits good solubility in interstitial fluid, to reach the target by longdistance diffusion. However, the effect of an administered drug is unpredictable, since it is most likely bound in the interstitial compartment on extracellular matrix. Depending on molecular structure and affinity, it is not constantly bioavailable but will be released by chance. However, administration, biophysical features, and bioavailability of a selected drug are not the sole problems. Its nephrotoxicity and possible side effects when 
acting in the nephrogenic zone and immature parenchyma must be analyzed even critically. Consequently, due to an unclear form of administration and unsure action of a drug on the related receptor, it is entirely unclear whether a therapeutic concept for prolongation of nephrogenesis will be available in the next future.

\section{Funding}

The project was supported by the Emeriti Research Fund, University of Regensburg, D-93053 Regensburg, Germany.

\section{Note}

Figures 1, 2, 3, and 4 rest on earlier published illustrations [135].

\section{Ethics approval and consent to participate}

Performed experiments are in accordance with the Animal Ethics Committee, University of Regensburg, Regensburg, Germany.

\section{Competing interests}

The author declares that he has no competing interests.

\section{Publisher's Note}

Springer Nature remains neutral with regard to jurisdictional claims in published maps and institutional affiliations.

\section{Received: 25 August 2017 Accepted: 20 November 2017}

\section{Published online: 07 December 2017}

\section{References}

1. Sulemanji M, Vakili K (2013) Neonatal renal physiology. Semin Pediatr Surg 22(4):195-198

2. Black MJ, Sutherland MR, Gubhaju L, Kent AL, Dahlstrom JE et al (2013) When birth comes early: effects on nephrogenesis. Nephrology (Carlton) 18(3):180-182

3. Stritzke A, Thomas S, Amin H, Fusch C, Lodha A (2017) Renal consequences of preterm birth. Mol Cell Pediatr 4(1):2

4. Luyckx VA, Perico N, Somaschini M, Manfellotto D, Valensise H, Cetin I et al (2017) A developmental approach to the prevention of hypertension and kidney disease: a report from the low birth weight and nephron number working group. Lancet 390(10092):424-428

5. Kandasamy Y, Smith R, Wright IM, Lumbers ER (2013) Extra-uterine growth in preterm infants: oligonephropathy and prematurity. Pediatr Nephrol 28(9):1791-1796

6. Gubhaju L, Sutherland MR, Yoder BA, Zulli A, Bertram JF et al (2009) Is nephrogenesis affected by preterm birth? Studies in a non-human primate model. Am J Physiol Renal Physiol 297(6):F1668-F1677

7. Fanos V, Castagnola M, Faa G (2015) Prolonging nephrogenesis in preterm infants: a new approach for prevention of kidney disease in adulthood. Iran J Kidney Dis 9(3):180-185

8. Minuth WW, Denk L (2012) Cell projections and extracellular matrix cross the interstitial interface within the renal stem/progenitor cell niche: accidental, structural or functional cues? Nephron Exp Nephrol 122(3-4): $131-140$

9. Krause M, Rak-Raszewska A, Pietilä I, Quaggin SE, Vainio S (2015) Signaling during kidney development. Cell 4(2):112-132

10. Minuth WW, Denk L (2014) Structural links between the renal stem/ progenitor cell niche and the organ capsule. Histochem Cell Biol 141(5): 459-471

11. Rumballe BA, Georgas KM, Combes AN, Ju AL, Gilbert T et al (2011) Nephron formation adopts a novel spatial topology at cessation of nephrogenesis. Dev Biol 360(1):110-122

12. Fanni D, Sanna A, Gerosa C, Puddu M, Faa G et al (2015) Each niche has an actor: multiple stem cell niches in the preterm kidney. Ital J Pediatr 41:78

13. El-Dahr SS, Li Y, Liu J, Gutierrez E, Hering-Smith KS, Signoretti S, Pignon JC, Sinha S, Saifudeen Z (2017) p63+ ureteric bud tip cells are progenitors of intercalated cells. JCI Insight 2:9

14. Kloth S, Aigner J, Brandt E, Moll R, Minuth WW (1993) Histochemical markers reveal an unexpected heterogeneous composition of the renal embryonic collecting duct epithelium. Kidney Int 44(3):527-536
15. Park HC, Yasuda K, Kuo MC, Ni J, Ratliff B et al (2010) Renal capsule as stem cell niche. Am J Physiol Renal Physiol 298(5):F1254-F1262

16. Hilliard SA, El-Dahr SS (2016) Epigenetics mechanisms in renal development. Pediatr Nephrol 31(7):1055-1060

17. Riccio P, Cebrian C, Zong H, Hippenmeyer S, Constantini F (2016) Ret and Etv promote directed movements of progenitor cells during renal branching morphogenesis. PLoS Biol 14(6):e1002382

18. Sanna A, Fanos V, Gerosa C, Vinci L, Puddu M et al (2015) Immunohistochemical markers of stem/progenitor cells in the developing human kidney. Acta Histochem 117(4-5):437-443

19. Combes AN, Davies JA, Little MH (2015) Cell-cell interactions driving kidney morphogenesis. Curr Top Dev Biol 112:467-508

20. Da Sacco S, Thornton ME, Petrosyan A, Lavarreda-Pearce M, Sedrakyan S et al (2017) Direct isolation and characterization of human nephron progenitors. Stem Cells Transl Med 6(2):419-433

21. Meyer TN, Schwesinger C, Bush KT, Stuart RO, Rose DW et al (2004) Spatiotemporal regulation of morphogenic molecules during in vitro branching of the isolated ureteric bud: toward a model of branching through budding in the developing kidney. Dev Biol 275(1):44-67

22. Reginensi A, Enderle L, Gregorieff A, Johnson RL, Wrana JL et al (2016) A critical role for NF2 and the Hippo pathway in branching morphogenesis. Nat Commun 7:12309

23. Short KM, Smyth IM (2017) Imaging, analyzing and interpreting branching morphogenesis in the developing kidney. Results Probl Cell Differ 60:233-256

24. Al-Awqati Q, Goldberg MR (1998) Archtectural patterns in branching morphognesis in the kidney. Kidney Int 54(6):1832-1842

25. Song R, Lopez MLSS, Yosypiv IV (2017) Foxd1 is an upstream regulator of the renin-angiotensin system during metanephric kidney development. Pediatr Res 82(5):855-862

26. Yuri S, Nishikawa M, Yanagawa N, Jo OD, Yanagawa N (2017) In vitro propagation and branching morphogenesis from single ureteric bud cells. Stem Cell Reports 8(2):401-416

27. Chi L, Saarela U, Railo A, Prunskaite-Hyyryläinen R, Skovorodkin I et al (2011) A sectreted BMP antagonist, CER1, fine tunes the spatial organization of the ureteric bud tree during mouse kidney development. PLoS One 6(11): e27676

28. Mao Y, Francis-West P, Irvine KD (2015) Fat4/Dchs1 signaling between stromal and cap mesenchyme cells influences nephrogenesis and ureteric bud branching. Development 142(15):2574-2585

29. Gu Y, Zhao Y, Zhou Y, Xie Y, Ju P et al (2016) Zeb1 is a potential regulator of Six2 in the proliferation, apoptosis and migration of metanephric mesenchyme cells. Int J Mol Sci 17:8

30. Schumacher K, Klar J, Wagner C, Minuth WW (2005) Temporal-spatial co-localisation of tissue transglutaminase (Tgase2) and matrix metalloproteinase-9 (MMP-9) with SBA-positive micro-fibers in the embryonic kidney cortex. Cell Tissue Res 319(3):491-500

31. Riggins KS, Mernaugh G, Su Y, Quaranta V, Koshikawa N et al (2010) MT1-MMP-mediated basement membrane remodeling modules renal development. Exp Cell Res 316(17):2993-3005

32. McGuire JK, Harju-Baker S, Rims C, Sheen JH, Liapis H (2012) Matrilysin (MMP-7) inhibition of BMP-7 induced renal tubular branching morphogenesis suggests a role in the pathogenesis of human renal dysplasia. J Histochem Cytochem 60(3):243-253

33. Zhang Z, Xing J, Gong R, Chin YE, Zhuang S (2009) Transglutaminase-1 regulates renal epithelial cell proliferation through activation of Stat-3. J Biol Chem 284(5):3345-3353

34. Antonyak MA, Li B, Regan AD, Feng Q, Dusaban SS et al (2009) Tissue transglutaminase is an essential participant in the epidermal growth factor-stimulated signaling pathway leading to cancer cell migration and invation. J Biol Chem 284(27):17914-17925

35. Keillor JW, Apperley KY (2016) Transglutaminase inhibitors: a patent review. Expert Opin Ther Pat 26(1):49-63

36. Minuth WW, Denk L, Miess C, Glashauser A (2011) Peculiarities of the extracellular matrix in the interstitium of the renal stem/progenitor cell niche. Histochem Cell Biol 136(3):321-334

37. Minuth WW, Denk L (2012) Illustration of extensive extracellular matrix at the epithelial-mesenchymal interface within the renal stem/progenitor cell niche. BMC Clin Pathol 12:16

38. Schumacher K, Strehl R, de Vries U, Groene HJ, Minuth WW (2002) SBApositive fibers between the CD ampulla, mesenchyme and renal capsule. J Am Soc Nephrol 13(10):2446-2453 
39. Schumacher K, Strehl R, Minuth WW (2003) Characterization of micro-fibers at the interface between the renal collecting duct ampulla and the cap condensate. Nephron Exp Nephrol 95:e43-e54

40. Ikeya M, Fukushima K, Kawada M, Onishi S, Furuta Y et al (2010) Cv2, functioning as a pro-BMP factor via twisted gastrulation, is required for early development of nephron precursors. Development 337(2):405-414

41. Minuth $W W$, Denk $L$ (2013) The interstitial interface within the renal stem/ progenitor cell niche exhibits an unique microheterogenous composition. Int J Mol Sci 14(7):13657-13669

42. Qiao J, Cohen D, Herzlinger D (1995) The metanephric blastema differentiates into collecting duct system and nephron epithelia in vitro. Development 121(10):3207-3214

43. Kanwar YS, Zheng ZL, Kumar A, Usman MI, Wada J et al (1996) D-glucose-induced dysmorphogenesis of embryonic kidney. J Clin Invest 98(11):2478-2488

44. Barasch J, Yang J, Qiao J, Tempst P, Erjument-Bromage $H$ et al (1999) Tissue inhibitor of metalloproteinase-2 stimulates mesenchymal growth and regulates epithelial branching during morphogenesis of the rat metanephros. J Clin Invest 103(9):1299-1307

45. Strehl R, Trautner V, Kloth S, Minuth WW (1999) Existence of a dense reticular meshwork surrounding the nephron inducer in neonatal rabbit kidney. Cell Tissue Res 298(3):539-548

46. Strehl R, Minuth WW (2001) Partial identification of the mab (CD)Amp1 antigen at the epithelial-mesenchymal interface in the developing kidney. Histochem Cell Biol 116(5):389-396

47. Minuth WW, Denk L (2015) Advanced fixation for transmission electron microscopy unveils special extracellular matrix within the renal stem/ progenitor cell niche. Methods Mol Biol 1212:21-37

48. Minuth WW, Denk L (2015) When morphogenetic proteins encounter special extracellular matrix and cell-cell connections at the interface of the renal stem/progenitor cell niche. Anatomy Cell Biology 48(1):1-9

49. Müller U, Wang D, Denda S, Meneses JJ, Pedersen RA et al (1997) Integrin aalpha8ßeta1 is critically important for epithelial-mesenchymal interactions during kidney morphogenesis. Cell 88(5):603-613

50. Brandenberger R, Schmidt A, Linton J, Wang D, Backus C et al (2001) Identification and characterization of a novel extracellular matrix protein nephronection that is associated with integrin alpha8ßeta1 in the embryonic kidney. J Cell Biol 154(2):447-458

51. Sato Y, Shimono LS, Nakano I, Norioka N et al (2013) Nephronectin binds to heparan sulfate proteoglycans via MAM domain. Matrix Biol 32:188-195

52. Uchiyama Y, Sakaguchi M, Terebayashi T, Inenaga T, Inoue S et al (2010) Kif26b, a kinesin family gene, regulates adhesion of the embryonic kidney mesenchyme. Proc Natl Acad Sci U S A 107(20):9240-9245

53. Nishinakamura R, Uchiyama Y, Sakaguchi M, Kujimura S (2011) Nephron progenitors in the metanephric mesenchyme. Pediatr Nephrol 26(9):1463-1467

54. Terabayashi T, Sakaguchi M, Shinmyozu K, Ohshima T, Johjima A et al (2012) Phosphorylation of Kif26b promotes its polyubiquitination and subsequent proteasomal degradation during kidney development. PLoS One 7(6):e39714

55. Domhan S, Ma L, Tai A, Anaya Z, Behesthti A et al (2011) Intercellular communication by exchange of cytoplasmic material vis tunneling nano-tube like structures in primary human renal epithelial cells. PLoS One 6(6):e21283

56. Combes AN, Lefevre JG, Wilson S, Hamilton NA, Little MH (2016) Cap mesenchyme cell swarming during kidney development is influenced by attraction, repulsion, and adhesion to the ureteric tip. Dev Biol 418(2):297-306

57. Holthöfer H (1987) Vascularization of the embryonic kidney. Detection of endothelial cells with Ulex europaeus I lectin. Cell Diff 20(1):27-31

58. Kloth S, Ebenbeck C, Monzer J, de Vries U, Minuth WW (1997) Three-dimensional organization of the developing vasculature of the kidney. Cell Tissue Res 287(1): 193-201

59. Munro DAD, Hohenstein P, Davies JA (2017) Cycles of vascular plexus formation within the nephrogenic zone of the developing mouse kidney. Sci Rep 7(1):3273

60. Gerosa C, Fanni D, Faa A, Van Eyken P, Ravarino A, Fanos V, Faa G (2017) Low vascularization of the nephrogenic zone of the fetal kidney suggests a major role for hypoxia in human nephrogenesis. Int Urol Nephrol. https:// doi.org/10.1007/s11255-017-1630-y

61. Han KH, Lim JM, Kim MY, Kim H, Madsen KM et al (2005) Expression of endothelial nitric oxide synthase in developing rat kidney. Am J Physiol Renal Physiol 288(4):F694-F702

62. Roker LA, Nemri K, Yu J (2017) Wnt7b signaling from the ureteric bud epithelium regulates medullary capillary development. J Am Soc Nephrol 28(1):250-259
63. Rymer C, Paredes J, Halt K, Schaefer C, Wiersch J et al (2014) Renal blood flow and oxygenation drive nephron progenitor differentiation. Am J Physiol Renal Physiol 307(3):F337-F345

64. Hemker SL, Sims-Lucas S, Ho J (2016) Role of hypoxia during nephrogenesis. Pediatr Nephrol 31(10):1571-1577

65. Oxburgh L, Muthukrishnan SD, Brown A (2017) Growth factor regulation in the nephrogenic zone of the developing kidney. Results Probl Cell Differ 60: 137-164

66. Hilliard SA, Yao X, El-Dahr SS (2014) Mdm2 is required for maintenance of the nephrogenic niche. Dev Biol 387(1):1-14

67. Carroll TJ, Das A (2013) Defining the signals that constitute the nephron progenitor niche. J Am Soc Nephrol 24:873-876

68. Tsujimura T, Idei M, Yoshikawa M, Takase O, Hishikawa K (2016) Roles and regulation of bone morphogenic protein-7 in kidney development and diseases. World J Stem Cells 8(9):288-296

69. Zhou P, Chen T, Fang Y, Wang H, Li M et al (2014) Down-regulated Six2 by knockdown of neurofibromin results in apoptosis of metanephric mesenchyme cells in vitro. Mol Cell Biochem 390(1-2):205-213

70. Kobayashi A, Valerius MT, Mugford JW, Carroll TJ, Self M et al (2008) Six2 defines and regulates a multipotent self-renewing nephron progenitor population throughout mammalian kidney development. Cell Stem Cell 3(2):169-181

71. Kopan R, Chen S, Little M (2014) Nephron progenitor cells: shifting the balance of self-renewal and differentiation. Curr Top Dev Biol 107:293-331

72. Piludu M, Fanos V, Congiu T, Piras M, Gerosa C et al (2012) The pine-cone body: an intermediate structure between the cap mesenchyme and the renal vesicle in the developing nof mouse kidney revealed by an ultrastructural study. J Matern Fetal Neonatal Med 25(5):72-75

73. Lander AD (2007) Morpheus unbound: reimagining the morphogen gradient. Cell 128(2):245-256

74. Kispert A, Vainio S, McMahon AP (1998) Wnt-4 is a mesenchymal signal for epithelial transformation of metanephric mesenchyme in the developing kidney. Development 125(21):4225-4234

75. Rak-Raszewska A, Hauser PV, Vainio S (2015) Organ in vitro culture: what have we learned about early kidney development? Stem Cells Int 2015: 959807

76. Lehtonen E (1975) Epithelio-mesenchymal interface during mouse kidney tubule induction in vivo. J Embryol Exp Morph 34(3):695-705

77. Saxen L, Lehtonen E (1978) Transfilter induction of kidney tubules as a function of the extent and duration of intercellular contacts. J Embryol Exp Morphol 47:97-109

78. Migliorini E, Thakar D, Kühnle J, Sadir R, Dyer DP et al (2015) Cytokines and growth factors cross-link heparin sulfate. Open Biol 5:8

79. Fairchild CL, Barna M (2014) Specialized filopodia: at the 'tip' of morphogen transport and vertebrate tissue patterning. Curr Opin Genet Dev 27:67-73

80. Costantini F, Shakya R (2006) GDNF/Ret signaling and the development of the kidney. BioEssays 28(2):117-127

81. Abuharbeid S, Czubayko F, Aigner A (2006) The fibroblast growth factor-binding protein FGF-BP. Int J Biochem Cell Biol 38(9):1463-1468

82. Swencki-Underwood B, Mills JK, Vennarini J, Boakye K, Luo J et al (2008) Expression and characterization of a human BMP-7 variant with improved biochemical properties. Protein Expr Purif 57(2):312-319

83. Pohl TL, Boergemann JH, Schwaerzer GK, Knaus P, Cavalcanti-Adam EA (2012) Surface immobilization of bone morphogenic protein 2 via a self-assembled monolayer formation induces cell differentiation. Acta Biomater 8(2):772-780

84. Creanga A, Glenn TD, Mann RK, Saunders AM, Talbot WS et al (2012) Scube/ You activity mediates release of dually lipid-modified Hedgehog signal in soluble form. Genes Dev 26(12):1312-1325

85. Gross JC, Boutros M (2013) Secretion and extracellular space travel of Wnt proteins. Curr Opin Genet Dev 23(4):385-390

86. Bandari S, Exner S, Ortmann C, Bachvarova V, Vortkamp A et al (2015) Sweet on Hedgehogs: regulatory roles of heparin sulfate proteoglycans in Hedgehog-dependent cell proliferation and differentiation. Curr Protein Pept Sci 16(1):66-76

87. Minuth WW, Denk L (2016) What is the functional background of filigree extracellular matrix and cell-cell connections at the interface of the renal stem/progenitor cell niche? J Pediatr Neonat Individual Med 5(1):e50115

88. Minuth WW, Denk L (2016) Special morphological features at the interface of the renal stem/progenitor cell niche force to reinvestigate transport of morphogens during nephron induction. BioResearch Open Access 5(1):49-60 
89. Akiyama T, Gibson MC (2015) Morphogen transport: theoretical and experimental controversies. Wiley Interdiscip Rev Dev Biol 4(2):99-112

90. Gheisari Y, Yokko T, Matsumoto K, Fukui A, Sugimoto N et al (2010) A thermoreversible polymer mediates controlled release of glial cell line-derived neurotrophic factor to enhance kidney regeneration. Artif Organs 34(8):642-647

91. Costantini F, Kopan R (2010) Patterning a complex organ: branching morphogenesis and nephron segmentation in kidney development. Dev Cell 18(5):698-712

92. Yan D, Lin X (2009) Shaping morphogen gradients by proteoglycans. Cold Spring Harb Perspect Biol 1(3):a002493

93. Rosines E, Schmidt HJ, Nigam SK (2007) The effect of hyaluronic acid size and concentration on branching morphogenesis and tubule differentiation in developing kidney culture systems: potential applications to engineering of renal tissues. Biomaterials 28(32):4806-4817

94. Shah MM, Sakurai H, Sweeney DE, Gallegos TF, Bush KT et al (2010) Hs2st mediated kidney kidney mesenchyme induction regulates early ureteric bud branching. Dev Biol 339(2):354-365

95. Shah MM, Sakurai H, Gallegos TF, Sweeney DE, Bush KT et al (2011) Growth factor-dependent branching of the ureteric bud is modulated by selective 6-O sulfation of heparin sulfate. Dev Biol 356(1):19-27

96. Nigam SK, Bush KT (2014) Growth factor-heparan sulfate "switches" regulating stages of branching morphogenesis. Pediatr Nephrol 29(4):727-735

97. Halt K, Vainio S (2014) Coordination of kidney organogenesis by Wnt signaling. Pediatr Nephrol 29(4):737-744

98. O'Brien LL, McMahon AP (2014) Induction and patterning of the metanephric nephron. Semin Cell Dev Biol 36:31-38

99. Luz M, Spanni-Müller S, Özhan G, Kagermeier-Schenk B, Rhinn M et al (2014) Dynamic association with donor cell filopodia and lipid-modification are essential features of Wnt8a during patterning of the zebrafish neuroectoderm. PLoS One 9(1):e84922

100. Stanganello E, Hagemann A, Mattes B, Sinner C, Meyen D et al (2015) Filopodia-based Wnt transport during vertebrate tissue patterning. Nat Commun 6:5846

101. Hsiung F, Ramirez-Weber FA, Iwaki DD, Kornberg TB (2005) Dependence of Drosophila wing immaginal disc cytonemes on Decapentaplegic. Nature 437(7058):560-563

102. Gill PS, Rosenblum ND (2006) Control of murine kidney development by sonic hedgehog and its GLI effectors. Cell Cycle 5(13):1426-1430

103. Chen X, Hou XM, Fan YF, Jin YT, Wang YL (2016) Sonic hedgehog protein regulates fibroblast growth factor 8 expression in metanephric explant culture from BALB/C mice: possible mechanisms associated with renal morphogenesis. Mol Med Rep 14(4):2929-2936

104. Bischoff M, Gradilla AC, Seijo I, Andres G, Rodriguez-Navas C et al (2013) Cytonemes are required for the establishment of a normal Hedgehog morphogen gradient in Drosophila epithelia. Nat Cell Biol 15(11):1269-1281

105. Sanders TA, Llagostatera E, Barna M (2013) Specialized filopodia direct long-range transport of SSH during vertebrate tissue patterning. Nature 497(7451):628-632

106. Liu Z, Shi H, Szymczak LC, Aydin T, Yun S et al (2015) Promotion of bone morphogenetic protein signaling by tetraspins and glycosingolipids. PLoS Genet 11(5):e1005221

107. Inabe M, Buszczak M, Yamashita YM (2015) Nanotubes mediate niche-stem-cell signaling in the drosophila testis. Nature 523(7560):329-332

108. Gurke S, Barroso JFV, Gerdes HH (2008) The art of cellular communication: tunneling nanotubes bridge the divide. Histochem Cell Biol 129(5):539-550

109. Kimura S, Hase K, Ohno H (2013) The molecular basis of induction and formation of tunneling nanotubes. Cell Tissue Res 352(1):67-76

110. Austefjord MW, Gerdes HH, Wang X (2014) Tunneling nanotubes: diversity in morphology and structure. Comm. Integr Biol 7(1):e27934

111. Gerdes HH, Pepperkok R (2013) Cell-to-cell communication: current views and future perspectives. Cell Tissue Res 352(1):1-3

112. Valente $S$, Rossi R, Resta L, Pasquinelli G (2015) Exploring the human mesenchymal stem cell tubule communication network through electron microscopy. Ultrastruc Pathol 39(2):88-94

113. Abounit S, Delage E, Zurzolo C (2015) Identification and characterization of tunneling nanotubes for intercellular trafficking. Curr Protoc Cell Biol 67:12. 10.1-12.10.21

114. Plotnikov EY, Khryapenkova TG, Galina SI, Sukhikh GT, Zorov DB (2010) Cytoplasm and organelle transfer between mesenchymal potent stromal cells and renal tubular cells in co-culture. Exp Cell Res 316(15):2447-2455

115. Alborizinia H, Shaikhkarami M, Hortschansky P, Wolf S (2016) BMP2 Tranfer to neighboring cells and activation of signaling. Traffic 17(9):1042-1053
116. Stanganello E, Scholpp S (2016) Role of cytonemes in Wnt transport. J Cell Sci 129(4):665-672

117. Benard M, Schapman D, Lebon A, Monterroso B, Bellenger M et al (2015) Structural and functional analysis of tunneling nanotubes (TnTs) using gCW STED and gconfocal approaches. Biol Cell 107(11):419-425

118. Bruno S, Camussi G (2013) Role of mesenchymal stem cell-derived microvesicles in tissue repair. Pediatr Nephrol 28(12):2249-2254

119. Borges FT, Reis LA, Schor N (2013) Extracellular vesicles: structure, function, and potential clinical uses in renal diseases. Braz. J Med Res 46(10):824-830

120. Bianchi F, Sala E, Donadei C, Capelli I, La Manna G (2014) Potential advantages of acute kidney injury management by mesenchymal stem cells. World J Stem Cells 6(5):644-650

121. Camussi G, Deregibus MC, Tetta C (2010) Paracrine/endocrine mechanism of stem cells on kidney repair: role of microvesicle-mediated transfer of genetic information. Curr Opin Nephrol Hypertens 19(1):7-12

122. Aggarwal S, Moggio A, Bussolati B (2013) Concise review: stem/progenitor cells for renal repair: current knowledge and perspectives. Stem Cells Transl Med 2(12):1011-1019

123. Bruno S, Porta S, Bussolati B (2016) Extracellular vesicles in renal tissue damage and regeneration. Eur J Pharmacol 790:83-91

124. Riazifar M, Pone EJ, Lötvall J, Zhao W (2017) Stem cell extracellular vesicles: extended messages of regeneration. Annu Rev Pharmacol Toxicol 57:125-154

125. Abitbol CL, DeFreitas MJ, Strauss J (2016) Assesment of kidney function in preterm infants: lifelong implications. Pediatr Nephrol 31(12):2213-2222

126. Ola R, Jakobson M, Kvist J, Perälä N, Kuure S et al (2011) The GDNF target Vsnl1 marks the ureteric tip. J Am Soc Nephrol 22(2):274-284

127. Malinauskas T, Aricescu AR, Lu W, Siebold C, Jones EY (2011) Modular mechanism of Wnt signaling inhibition by Wnt inhibitory factor 1. Nat Struct Mol Biol 18(8):886-893

128. Kornberg TB, Roy S (2014) Cytonemes as specialized signaling filopodia. Development 141(4):729-736

129. Kshitiz AJ, Suhail Y, Ahn EH, Goyal R, Hubbi ME et al (2015) Control of the interface between heterotypic cell populations reveal the mechanism of intercellular transfer of signaling proteins. Integr Biol 7(3):364-372

130. Minuth WW (2017) The rabbit nephrogenic zone in culture: past, present and future as a model to investigate causes of impaired nephrogenesis. J Pediatr Neonat Individual Med 6(1):e060111

131. Nishinakamura R, Sakaguchi M (2014) BMP signaling and its modifiers in kidney development. Pediatr Nephrol 29(4):681-686

132. Qi X, Okinaka Y, Nishita M, Minami Y (2016) Essential role of Wnt5a-Ror1/ Ror2 signaling in metanephric mesenchyme and urerteric bud formation. Genes Cells 21(4):325-334

133. Reidy KJ, Rosenblum ND (2009) Cell and molecular biology of kidney development. Semin Nephrol 29(4):321-337

134. Trueb B, Amann R, Gerber SD (2013) Role of FGFRL1 and other FGF signaling proteins in early kidney development. Cell Mol Life Sci 70(14): 2505-2518

135. Minuth WW (2017) View onto the nephrogenic zone before stem cell niches come apart: challenge for smart drug delivery. J Drug Res Dev 3(1): doi:http://dx.doi.org/10.16966/2470-1009.127. 